\title{
I'M DONE MY HOMEWORK: COMPLEMENT COERCION AND ASPECTUAL ADJECTIVES IN CANADIAN ENGLISH
}

\author{
PATRICK MURPHY \\ University of Toronto
}

\section{ABS TRACT}

Self-paced reading and eye-tracking studies have generally found that combining aspectual verbs (like begin and finish) with entity nouns (like the book or the coffee) is associated with increased reading times on and around the noun (McElree et al. 2001; Traxler et al. 2002; Pickering et al. 2005). This processing cost is widely interpreted as evidence of complement coercionaspectual verbs semantically select for an event (like dancing or the dance) and can take entity objects only if they are coerced into an event through a computationally costly process of type-shifting (Pustejovsky 1995; Jackendoff 1997). This paper presents an eye-tracking study of the Canadian English be done NP construction, e.g., I am done/finished my homework (not to be confused with the dialect-neutral I am done/finished with my homework) to mean I have finished my homework. Results suggest a processing penalty for entitydenoting nouns like the script (compared to event description nouns like the audition) in this construction, which supports Fruehwald \& Myler's (2015) proposal that done and finished in this construction are aspectual adjectives that behave like aspectual verbs in requiring complement coercion and typeshifting for entity-denoting nouns.

\section{[1] INTRODUCTION}

The focus of this paper is complement coercion, such as in the sentence the child began the book (Briscoe et al. 1990; Pustejovsky 1991, 1995; Jackendoff 1997; Asher 2011; Egg 2003). According to the literature on coercion, aspectual verbs like begin select as their complement an event description like to dance, dancing, or the dance. However, the book denotes an entity; such a mismatch can be solved if the entitydenoting noun is reinterpreted as an event involving that entity. In the case of the child began the book, the book is likely to be understood as reading the book or looking at the book (other interpretations, such as writing the book, are also possibilities depending on the subject and context). Note that the event interpretation of the book is specifically tied to its position as the complement of an aspectual verb, and is not universally available. As noted by Asher (2011), a sentence like the child's book 
will begin in two minutes (meaning the child's \{reading, writing, etc.\} of the book will begin in two minutes) is semantically odd. In addition to aspectual verbs, psychological verbs like enjoy have traditionally been analyzed as event-selecting verbs that require complement coercion for entity-denoting objects (although more recently, Katsika et al. 2012 have presented evidence that psychological verbs do not fit into this category). The term coercion was introduced to linguistics by Moens \& Steedman (1988), and it has also been used for mass/count and aspectual mismatches.

Early processing studies of complement coercion using self-paced reading and eye-tracking techniques discovered that the combination of event-selecting verb and entity-denoting NP is slower or more difficult to process compared to other verb and object combinations (McElree et al. 2001; Traxler et al. 2002; Pickering et al.2005-but see also de Almeida 2004). These early studies generally presented or cited the enriched composition view of coercion, which involves a (computationally costly) semantic repair mechanism, commonly called type-shifting, acting on the noun to satisfy the selectional requirements of the verb (Piñango et al. 1999; Pylkkänen \& McElree 2006; Pustejovsky 1991, 1995; Jackendoff 1997; Katsika et al. 2012). However, these studies primarily focused on providing psycholinguistic evidence that these coercion sentences are unique, rather than distinguishing between different theories about what coercion involves.

Later studies used reading measures (and other evidence) to delve more deeply into understanding the mechanisms underlying coercion. One alternative possibility is that complement coercion involves extra structure in the form of a silent VP between the coercion verb and the noun, and that this (rather than an operation such as type-shifting) is the reason for the increased processing requirements of coercion (de Almeida \& Dwivedi 2008). However, Pylkkänen \& McElree (2006) present evidence against coercion involving a silent VP, including an inability to adverbially modify the supposed silent VP. Another possible explanation that does not rely on type-shifting is that the processing effect of coercion is a result of pragmatically having to infer an event from an entity (e.g., to determine whether began the book refers to reading, writing, looking at, etc.). However, multiple studies find that varying the need to infer the event (Traxler et al. 2005 by providing a context sentence, and Frisson \& McElree 2008 by choosing coercion sentences with more or fewer possible interpretations) does not affect the processing effect of coercion. The type-shifting view of coercion remains common in the literature (e.g., Katsika et al. 2012), although note that the nature of complement coercion is still an ongoing area of research and there are other current proposals (Asher 2011; Piñango \& Deo 2016).

The linguistic phenomenon of interest in this paper is the be done NP construction seen in (1) and (2), which is found in Canadian English and in a few varieties of American English, specifically in Philadelphia and Vermont (Yerastov 2008, 2012; 
Fruehwald \& Myler 2015). Both done and finished are possible.

(1) I'm finished my homework.

(2) I'm done my homework.

The meaning is equivalent to the aspectual verb finish in the perfect, as in (3).

(3) I've finished my homework.

The meaning of the Canadian construction has overlap with the (dialect-neutral) prepositional be done with NP construction in (4) and (5), but they are not the same. The Canadian construction requires that the object be completely finished, while the prepositional construction also allows cases where the subject has lost interest (if someone completes half of their homework and moves to another task, they are done with their homework but not done their homework).

(4) I'm finished with my homework.

(5) I'm done with my homework.

The difference in interpretation between the Canadian construction and the prepositional construction is evidence that the Canadian construction should not be analysed as involving a silent preposition, or at least not one equivalent to with. Yerastov $(2008,2012)$ argues that the Canadian construction is best analyzed as the regular English perfect like in (3) but with a non-standard auxiliary (be instead of have), based in part on parallels with the be-perfect in Scottish English. However, Fruehwald \& Myler (2015) argue against the be-perfect analysis for this Canadian English construction for a variety of reasons. Notably, all is compatible with the Canadian construction (6) and with adjectives (7) but not perfect participles (8).

(6) I'm all done my homework.

(7) I'm all ready for school.

(8) *I've all done my homework.

In addition, they note that the Canadian construction (9) and adjectives (10) can be embedded under the perfect, but the perfect itself (11) cannot be embedded under another perfect.

(9) I have been done my homework for a while now.

(10) I have been ready for school for a while now.

(11) *I have had done my homework for a while now. 
Instead, Fruehwald \& Myler propose that the Canadian construction involves an adjective that directly takes as its complement an NP (without a silent intervening PP or VP). This is not common in English, but is also not unprecedented (as in be worth NP). Because done and finished are adjectival versions of aspectual verbs, Fruehwald \& Myler argue that these aspectual adjectives semantically select for an event description and require complement coercion and type-shifting for interpretation of entity-denoting nouns. Given that complement coercion with aspectual verbs has been investigated and supported with reading measures, Fruehwald \& Myler's proposal should also be testable with reading measures.

The present study is an eye-tracking experiment testing this analysis of the Canadian construction by comparing reading times of entity-denoting nouns and event description nouns in the Canadian construction, with the hypothesis that entity-denoting nouns will be associated with more processing difficulty. Sentences in the dialect-neutral prepositional construction will also be tested, although Fruehwald \& Myler's analysis does not have any specific predictions here. Note that this paper will be assuming the type-shifting or enriched composition analysis of coercion, in line with the language used by Fruehwald \& Myler in their analysis, although this experiment was designed to determine whether the Canadian construction exhibits coercion effects, rather than to distinguish between different reasons or explanations for coercion effects (like Traxler et al. 2005 and Frisson \& McElree 2008 comparing pragmatic and semantic analyses).

\section{[2] CANADIAN ENGLISH BE DONE NP EXPERIMENT}

This experiment tests whether there is a penalty for entity nouns compared to event nouns in the Canadian English be done NP construction and in the dialectneutral be done with NP construction.

\section{[2.1] Method}

\section{Participants}

Thirty-six native speakers of Canadian English (mean age $=25, \mathrm{sd}=11$ ), primarily from Southern Ontario, took part in this experiment at the University of Toronto, for $\$ 10$ or course credit. An additional 28 participants took part but were excluded from analysis: five due to excessive blinks or track loss, 21 for not being native speakers of Canadian English, ${ }^{1}$ and two for indicating that the be done NP construction did not sound natural or acceptable to them. They provided written informed consent prior to partaking in the experiment.

[1] Students participating for course credit were not prescreened for language background, to avoid restricting opportunities for course credit. 


\section{Items}

The stimuli for this experiment contrasted event description nouns (like the audition and the interview) with entity-denoting nouns (like the script and the resume) in the Canadian English be done NP construction and in the dialect-neutral be done with NP construction. Crossing these two factors resulted in four conditions, as seen below.

(12) After the girl was finished the fight against the playground bully, she went for a walk. (Canadian construction + event object)

(13) After the girl was finished the comic about flying superheroes, she went for a walk. (Canadian construction + entity object)

(14) After the girl was finished with the fight against the playground bully, she went for a walk. (Prepositional construction + event object)

(15) After the girl was finished with the comic about flying superheroes, she went for a walk. (Prepositional construction + entity object)

In total there were 32 such quadruplets. They all followed a similar structure of a preposed subordinate clause (which included the construction of interest) and a shorter main clause. However, there were also differences between the quadruplets: half had a singular subject and half a plural subject, half had the adjective done and half had the adjective finished, and they also varied regarding their conjunction and temporal reference (past with after, present with because, and future with when). Participants only saw one sentence from each quadruplet, which means that they saw either an event description object or an entity-denoting object. The object that they did not see could be reused and shown to them in a later quadruplet, and so in the 32 quadruplets there were a total of 16 event description nouns and 16 entity-denoting nouns (rather than 32 of each). The nouns are provided below.

(16) Entities: comic, resume, prescription, script, report, autobiography, article, album, juice, coffee, hamburger, message, letters, essay, champagne, software

(17) Events: fight, interview, presentation, audition, lecture, speech, conversation, concert, party, celebration, visit, gala, battle, competition, game, discussion

The mean length of the event nouns (7.625 characters) and entity nouns (7.25 characters) did not differ significantly, according to an independent $t$-test $\left(\mathrm{t}_{29.293}\right.$ $=0.40018, p=0.69$ ). In addition, the (log-transformed) frequencies of the event nouns and entity nouns did not differ significantly in the usenet-based Hyperspace Analogue to Language (HAL) corpus (event: 9.69, entity: 9.47, $t_{28.157}=-$ 
$0.39698, \mathrm{p}=0.69$ ) or in the movie subtitle-based SUBTLEX corpus (event: 3.15, entity: $\left.2.92, \mathrm{t}_{29.982}=1.1263, \mathrm{p}=0.27\right)$, both of which were accessed through the English Lexicon Project (Balota et al. 2007). Reading times would not be expected to vary between the two groups of nouns as a result of their length or frequency.

\section{Procedure}

Participants were seated in a height-adjustable chair wearing the EyeLink II headmounted video-based eye-tracker (which had a sampling frequency of $250 \mathrm{~Hz}$ ). The text was displayed on a computer screen in black 25 pt Times New Roman font on a white background. They were instructed to read each sentence at a normal reading pace, well enough to understand the sentence and answer comprehension questions (which followed every trial). Comprehension questions were asked about different parts of the sentence (the subject, the object, or the event in the second clause). For example, the comprehension question after When the musician is finished the concert at the new venue, he will take some time off asked what the musician will do, and the participant chose from a set of options. The eyetracker was calibrated using a series of three fixed targets across the display at the beginning of the experiment, and recalibration was performed later on when judged necessary by the experimenter.

Each trial began with a fixation target on the screen in the position that would be taken by the first letter of the sentence. Participants were instructed to fix their gaze on this target, at which point the experimenter started the trial and made the sentence appear on the screen, all on one line. After reading silently, participants pressed the trigger at the back of a game controller to bring up the comprehension question, which they answered with the triggers as well. Feedback was not provided. After selecting their response, participants were immediately brought back to the screen with the fixation target, and the next trial started once they fixated on that target. Viewing was binocular, but only the left eye was recorded. All participants performed very well on the comprehension questions.

Participants encountered the stimuli in a random order, mixed in with stimuli from three other eye-tracking experiments that they were simultaneously participating in. The present experiment comprised 32 of the 120 total sentences that each participant saw. ${ }^{2}$ Each participant was assigned to one of four lists, which affected which of the four sentences in each stimulus quadruplet they saw. The entire session took approximately 30 minutes.

\section{[2.2] Results}

Each sentence was divided into six regions, as in (18). Region 3 was the object, and thus the critical region.

[2] Regarding order effects, reading times for this experiment (total time, as defined below, for all interest areas in this experiment) were $9 \%$ faster in the second half of the 120 -trial session than the first half. 
(18) $\left[{ }_{R 1}\right.$ After the girl] [ $\left[_{R 2}\right.$ was finished (with) $]\left[{ }_{R 3}\right.$ the fight $]\left[{ }_{R 4}\right.$ against $]\left[{ }_{R 5}\right.$ the playground bully,] [R6 she went for a walk.]

Five reading measures are reported here for the critical region (R3): first-pass time (a.k.a gaze duration), first-pass regression ratio, go-past time (a.k.a. regression path duration), second-pass time, and total time. First-pass time is the time from first entering the region before moving on or looking back; first-pass regression ratio is the likelihood of reading a region for the first time and then rereading an earlier region; go-past time is the time from first entering a region until moving on to a later region (including time spent re-reading an earlier region); second-pass time is the time from entering the region for a second time before moving on or looking back; and total time is all of the time spent in the area regardless of when it happened. The reading measures selected were those used in previous eye-tracking studies of coercion (Traxler et al. 2002, 2005; Pickering et al. 2005).

Manual cleanup of the data was performed to remove trials with blinks or track loss on the critical region (or one saccade away from it) on first-pass reading and trials where the fixations indicate that the participant did not read the whole sentence (for example, they only fixated at the beginning of the sentence and then pressed the trigger to move on, possibly accidentally). Comprehension questions were used to encourage participants to read the simuli carefully, but incorrect comprehension questions were not used to exclude trials (on multiple occasions, participants remarked to the experimenter that they pressed the wrong button, suggesting that they were paying attention). In total, $11.2 \%$ of the trials were deleted.

The five reading measures for $\mathrm{R} 3$ are shown below, separated by construction for better visibility. Keep in mind when looking at the results that a longer reading time (or more regressions) for entities compared to events is the finding that suggests coercion effects. In the tables, FP Time is first-pass time, FP Reg is firstpass regressions, GP Time is go-past time, and SP time is second-pass time.

TABLE 1: Scores for critical region (R3) for be done NP

\begin{tabular}{llllll}
\hline Object & FP Time & FP Reg & GP Time & SP Time & Total Time \\
\hline Entity & $381 \mathrm{~ms}$ & $27.4 \%$ & $545 \mathrm{~ms}$ & $319 \mathrm{~ms}$ & $650 \mathrm{~ms}$ \\
Event & $359 \mathrm{~ms}$ & $25.4 \%$ & $480 \mathrm{~ms}$ & $263 \mathrm{~ms}$ & $586 \mathrm{~ms}$ \\
\hline
\end{tabular}


TABLE 2: Scores for critical region (R3) for be done with NP

\begin{tabular}{llllll}
\hline Object & FP Time & FP Reg & GP Time & SP Time & Total Time \\
\hline Entity & $330 \mathrm{~ms}$ & $17.8 \%$ & $395 \mathrm{~ms}$ & $270 \mathrm{~ms}$ & $494 \mathrm{~ms}$ \\
Event & $324 \mathrm{~ms}$ & $20.5 \%$ & $411 \mathrm{~ms}$ & $288 \mathrm{~ms}$ & $518 \mathrm{~ms}$ \\
\hline
\end{tabular}

$\mathrm{R}$ ( $\mathrm{R}$ Core Team 2017) and lmerTest (Kuznetsova et al. 2017) were used to perform a linear (or logistic, in the case of first-pass regressions) mixed effects analysis of the relationship between each of these five reading measures, the noun type, and the construction. Fixed effects were noun type (event or entity) and construction (Canadian or prepositional). The contrast coding chosen for these two categorical factors (noun type and construction) was simple coding, rather than R's default treatment coding, in order to test main effects rather than simple effects. This means that the effect of noun type presented below is tested across levels of construction, and the effect of construction is similary tested across noun types. These are the desired hypotheses to be tested (in addition to the interaction between noun type and construction). For these two-level factors, this involved coding one level as -0.5 and the other level as 0.5. "Event" was the reference level $(-0.5)$ for noun type and "prepositional" was the reference level for construction.

The analyses were planned with the maximal random effects structure justified by the experimental design (Barr et al. 2013), which means random intercepts for subjects and items ( 36 participants and 32 nouns), along with by-subject random slopes for noun type and construction, and by-item random slopes for construction (by-item slopes for noun type were not possible because each item was either one noun type or the other). This random effect structure was used for first-pass time, go-past time, and total time. For first-pass regression ratio and second-pass time, a model with random slopes failed to converge, and so the results from a simpler model (with only random intercepts) will be presented instead.

The analyses for each of the five reading measures are presented below, as well as violin plots for each of the five measures (data averaged by participant for each condition). The significance markers are as follows: “***” $<0.001<$ “**" < $0.01<" * * 0.05<"$ " " $<0.1$. 
First-pass time
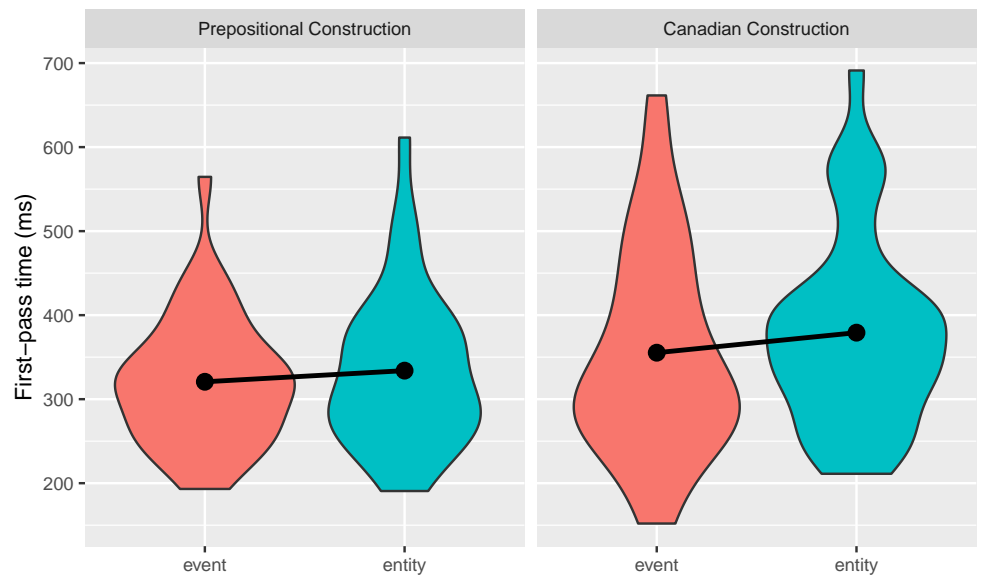

FIGURE 1: Violin plot, first-pass time, critical region (R3)

TABLE 3: Mixed effects model, first-pass time, critical region (R3)

\begin{tabular}{lllllll}
\hline Fixed Effects & Estimate & Std. Error & df & t-value & $\operatorname{Pr}(>|t|)$ & Sig \\
\hline (Intercept) & 348.73 & 14.500 & 37.34 & 24.046 & $<2 \mathrm{e}-16$ & *** \\
Noun Type & 17.21 & 13.52 & 32.51 & 1.273 & 0.21193 & \\
Construction & 41.27 & 12.61 & 87.02 & 3.273 & 0.00153 & $* *$ \\
Noun:Construction & 15.76 & 22.83 & 644.13 & 0.690 & 0.49024 & \\
\hline
\end{tabular}

First-pass time is the time from first entering the region before moving on or looking back.

In interpreting this model (and following models), attention should primarily be paid to the main effect of noun type and the interaction between noun type and construction. A main effect of noun type (with a positive estimate) would indicate a coercion effect across both constructions, while an interaction (with a positive estimate) could indicate stronger coercion effects in the Canadian construction, although neither the main effect nor the interaction were found at a statistically significant level for this reading measure.

A main effect of construction would indicate that one construction resulted in overall longer reading times on the noun, across noun types. This was statistically significant in this reading measure (with a positive estimate, meaning that the Canadian construction had overall longer reading times for the noun), although 
this is of less interest because it is not relevant for coercion.

First-pass regressions
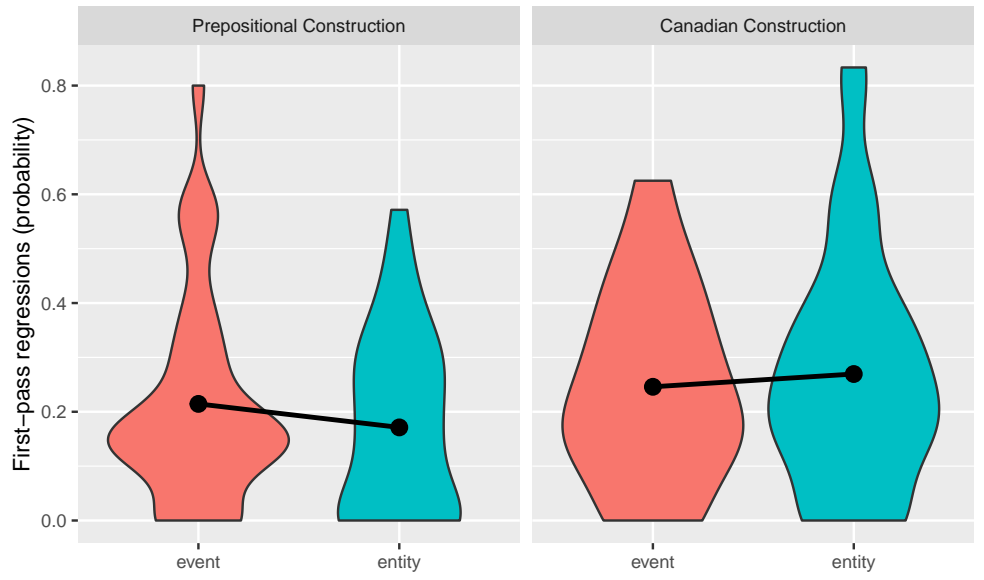

FIGURE 2: Violin plot, first-pass regressions, critical region (R3)

TABLE 4: Mixed effects model, first-pass regressions, critical region (R3)

\begin{tabular}{llllll}
\hline Fixed Effects & Estimate & Std. Error & z-value & $\operatorname{Pr}(>|z|)$ & Sig \\
\hline (Intercept) & -1.32892 & 0.13291 & -9.999 & $<2 \mathrm{e}-16$ & $* * *$ \\
Noun Type & -0.05234 & 0.18142 & -0.289 & 0.77295 & \\
Construction & 0.42588 & 0.16096 & 2.646 & 0.00815 & $* *$ \\
Noun:Construction & 0.32141 & 0.32141 & 1.000 & 0.31732 & \\
\hline
\end{tabular}

First-pass regression ratio is the likelihood of reading a region for the first time and then re-reading an earlier region. As with first-pass time, there was a significant effect of construction but no effect of noun type and no interaction between construction and noun type.

Go-past time

TABLE 5: Mixed effects model, go-past time, critical region (R3)

\begin{tabular}{lllllll}
\hline Fixed Effects & Estimate & Std. Error & df & t-value & $\operatorname{Pr}(>|t|)$ & Sig \\
\hline (Intercept) & 455.66 & 23.19 & 43.31 & 19.646 & $<2 \mathrm{e}-16$ & ***
\end{tabular}




\begin{tabular}{lllllll}
\hline Fixed Effects & Estimate & Std. Error & df & t-value & $\operatorname{Pr}(>|t|)$ & Sig \\
\hline Noun Type & 26.16 & 24.73 & 32.01 & 1.058 & 0.2982 & \\
Construction & 103.69 & 20.75 & 49.45 & 4.998 & $7.66 \mathrm{e}-06$ & $* * *$ \\
Noun:Construction & 82.82 & 36.23 & 70.75 & 2.286 & 0.0253 & $*$ \\
\hline
\end{tabular}

Go-past time is the time from first entering a region until moving on to a later region (including time spent re-reading an earlier region). The analysis found a significant effect of construction, no effect of noun type, and an interaction between construction and noun type. This interaction is important. Post-hoc analyses found that entity nouns were read significantly longer than event nouns in the Canadian construction according to a by-subjects analysis (paired t-test: $t_{35}=-2.240, p=0.032$ ), although this did not quite reach significance in a by-items analysis (independent $t$-test: $t_{23.091}=-1.673, p=0.108$ ). There was no difference between noun types in the prepositional construction in either the by-subjects $\left(\mathrm{t}_{35}=0.77491, \mathrm{p}=0.444\right)$ or by-items analysis $\left(\mathrm{t}_{29.77}=0.813, \mathrm{p}=0.423\right)$.

Second-pass time

TABLE 6: Mixed effects model, second-pass time, critical region (R3)

\begin{tabular}{lllllll}
\hline Fixed Effects & Estimate & Std. Error & $\mathrm{df}$ & $\mathrm{t}$-value & $\operatorname{Pr}(>|\mathrm{t}|)$ & Sig \\
\hline (Intercept) & 283.948 & 7.562 & 30.462 & 37.551 & $<2 \mathrm{e}-16$ & $* * *$ \\
Noun Type & 18.703 & 13.775 & 444.782 & 1.358 & 0.17522 & \\
Construction & 13.084 & 13.770 & 443.439 & 0.950 & 0.34251 & \\
Noun:Construction & 73.684 & 27.508 & 437.494 & 2.679 & 0.00767 & $* *$ \\
\hline
\end{tabular}

Second-pass time is the time from entering the region for a second time before moving on or looking back. The analysis found no effect of construction or noun type, but there was an interaction between construction and noun type.

Post-hoc analyses using independent t-tests found that entity nouns had a significantly longer second-pass time than event nouns in the Canadian construction (by-items: $t_{19.041}=-2.552, p=0.019$ ) but there was no difference between noun types in the prepositional construction (by-items: $\left.\mathrm{t}_{24.526}=0.933, \mathrm{p}=0.360\right)^{3}$

Total time

[3] Not all trials had a second-pass time. By-subjects analysis was not possible due to missing data, and so only by-items analysis is presented. 

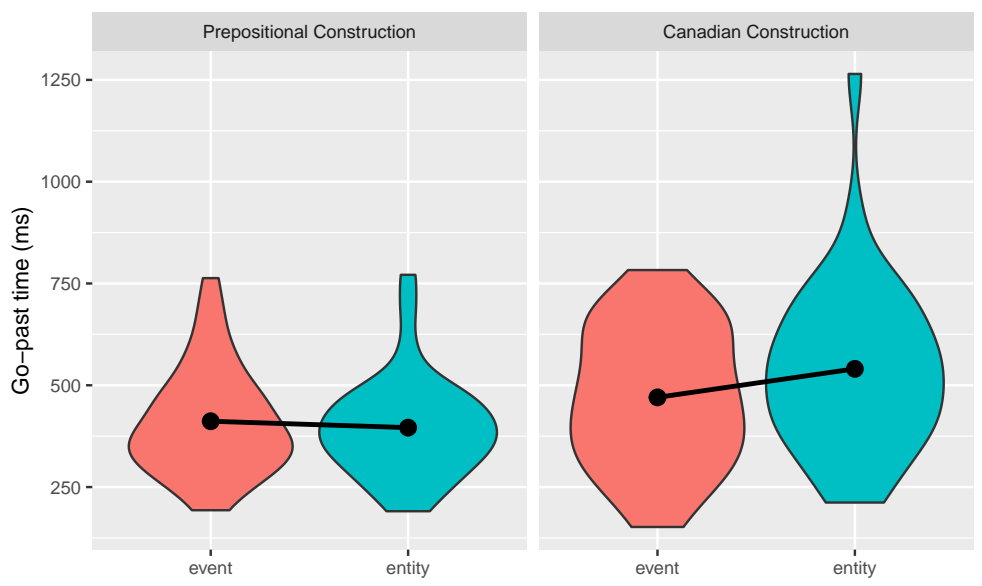

FIGURE 3: Violin plot, go-past time, critical region (R3)

TABLE 7: Mixed effects model, total time, critical region (R3)

\begin{tabular}{lllllll}
\hline Fixed Effects & Estimate & Std. Error & df & t-value & $\operatorname{Pr}(>|t|)$ & Sig \\
\hline (Intercept) & 560.65 & 32.14 & 47.73 & 17.443 & $<2 \mathrm{e}-16$ & *** \\
Noun Type & 19.51 & 36.28 & 31.97 & 0.538 & 0.5945 & \\
Construction & 106.62 & 22.32 & 107.87 & 4.777 & $5.64 \mathrm{e}-06$ & $* * *$ \\
Noun:Construction & 78.93 & 43.25 & 157.08 & 1.825 & 0.0699 & . \\
\hline
\end{tabular}

Total time is all of the time spent in the area regardless of when it happened. The analysis found a significant effect of construction, no effect of noun type, and a marginal interaction between construction and noun type. A visual inspection of the data finds the longest total time for entities in the Canadian construction.

\section{Summary}

The following table shows a summary of the significant results on each measure. The relevance of these findings will be discussed below. In the table, FP Time is first-pass time, FP Reg is first-pass regressions, GP Time is go-past time, and SP time is second-pass time.

TABLE 8: Summary of results (significance codes: $0 * * * 0.001 * * 0.01 * 0.05$ marginal $0.1 \mathrm{n} / \mathrm{s} 1)$

\begin{tabular}{llllll}
\hline Effect & FP Time & FP Reg & GP Time & SP Time & Total Time \\
\hline Noun Type & $\mathrm{n} / \mathrm{s}$ & $\mathrm{n} / \mathrm{s}$ & $\mathrm{n} / \mathrm{s}$ & $\mathrm{n} / \mathrm{s}$ & $\mathrm{n} / \mathrm{s}$ \\
Construction & $* *$ & $* *$ & $* * *$ & $\mathrm{n} / \mathrm{s}$ & $* * *$ \\
Interaction & $\mathrm{n} / \mathrm{s}$ & $\mathrm{n} / \mathrm{s}$ & $*$ & $* *$ & marginal \\
\hline
\end{tabular}



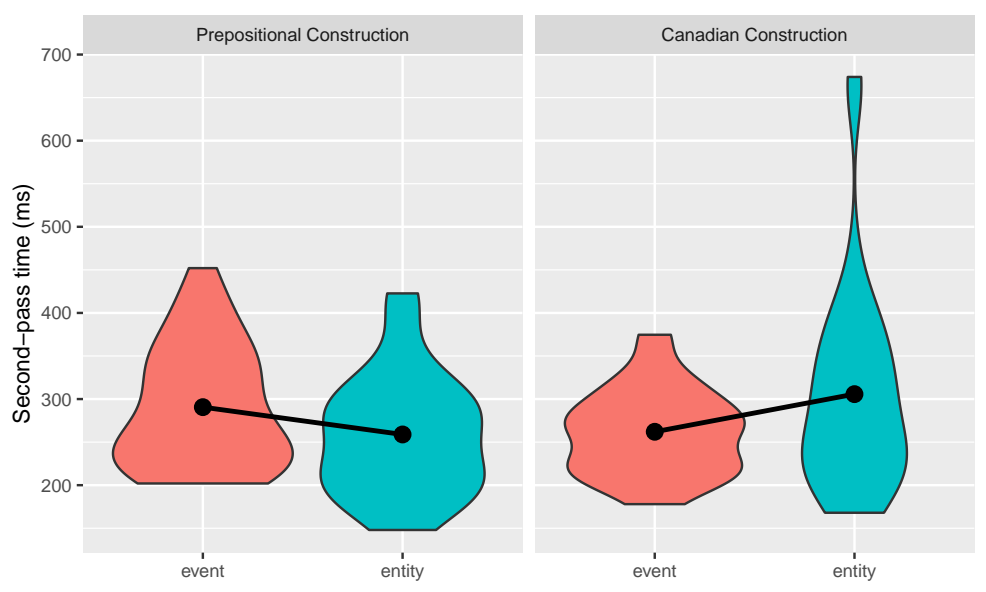

FIGURE 4: Violin plot, second-pass time, critical region (R3)

past time and second-pass time) there was a significant interaction between noun type and construction, and in one other measure (total time) the interaction was marginal. The meaning and implication of this interaction will be discussed below, but first it is important to mention that failure to find this result on every measure is not unexpected. Go-past time is based on first-pass time and first-pass regressions, so smaller (non-significant) trends in those measures can compound into a larger effect that is visible (and statistically significant) in go-past time. The measures where a significant or marginal interaction was found (go-past time, secondpass time, and total time) in this experiment line up with the reading measures where a significant or marginal coercion effect was found in Traxler et al. (2002), the original study establishing coercion effects in eye-tracking.

As for the meaning of this interaction, post-hoc t-tests showed that the interaction was a result of entity-denoting nouns having longer go-past time and second-pass time in the Canadian construction but there being no difference between noun types in the prepositional construction. The penalty for entity-denoting nouns found in the Canadian construction on these measures is consistent with the processing effects of coercion, and so this result supports Fruehwald \& Myler's 2015 proposal that the adjectives in this construction select for an event description and require complement coercion for interpretation of an entity-denoting noun (in a similar manner to finish and other aspectual verbs).

The lack of difference between the noun types in the prepositional context could indicate that the preposition anticipates the upcoming type-shifting operation and attenuates the processing cost, or that it eliminates the selectional requirement for an event description (and thus the need for type-shifting when en- 

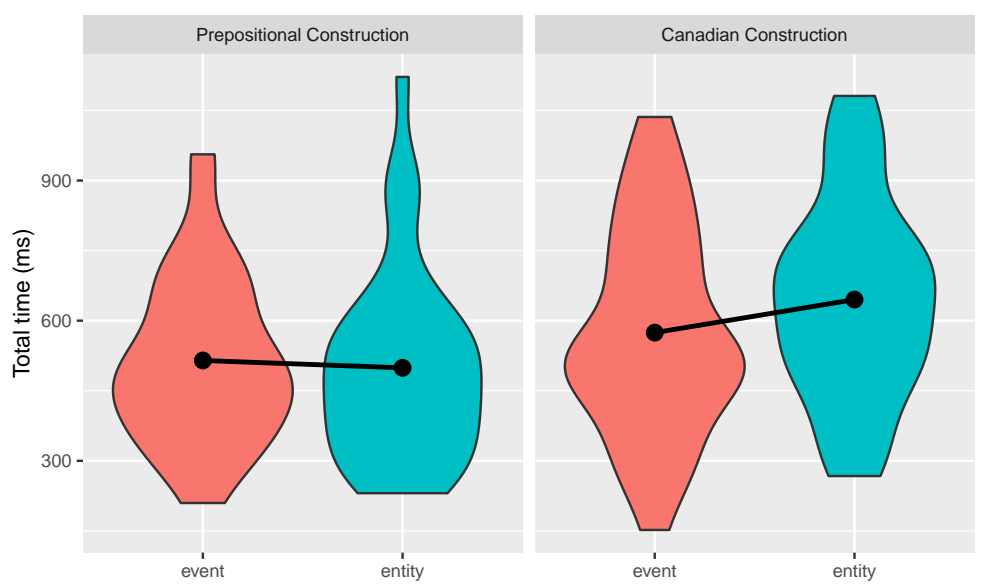

FIGURE 5: Violin plot, total time, critical region (R3)

countering an entity-denoting noun). Various authors have remarked that adding prepositions to aspectual verbs changes the interpretation in ways that are relevant for coercion. Verspoor (1997) compares begin and begin on, arguing that the prepositional version "indicates only that something is being done with the NP object, leaving a more specific interpretation to be established using contextual information"-which could mean anticipating the type-shifting operation. ${ }^{4}$ Looking at the equivalent in Dutch, beginnen aan, Honselaar (1980) (cited and translated in Sweep 2012) argues that beginnen needs to be combined with an event object while beginnen aan combines much more freely; Sweep (2012) argues that beginnen aan "makes logical metonymy [referring to complement coercion sentences like "Mary began the book'] easier to understand". A deeper semantic analysis of coercion (or the lack of coercion) in the done with NP prepositional construction is outside the scope of this paper, although these precedents in the literature regarding prepositions and aspectual verbs does support the plausibility of the preposition anticipating type-shifting or eliminating the need for type-shifting.

\section{[3] CONCLUSION}

Previous literature has shown that entity-denoting objects have a processing cost when following event-selecting verbs (like begin the book). This cost has been associated with the need to coerce and reinterpret the book as an event in that context

[4] This has precedent in the processing literature. Processing difficulty related to mass-to-count coercion (like in yesterday, I bought imported beers [...]) has been shown to be attenuated when a numeral is provided before the object to make the reader anticipate a count interpretation (yesterday, I bought three imported beers [...]) (Frazier \& Frisson 2005). 
(begin [the book] to begin [reading the book]). Results from an eye-tracking study presented here found that entity-denoting objects also have a processing cost in the Canadian English be done NP construction (I'm done the book), suggesting that these aspectual adjectives behave similarly to aspectual verbs in selecting for event descriptions and requiring coercion for interpretation of entity-denoting nouns, as was argued by Fruehwald \& Myler (2015).

\section{ACKNOWLEDGMENTS}

I would like to thank Margaret Grant, Philip Monahan, Guillaume Thomas, and Suzi Lima for their involvement in this project, as well as Mercedeh Mohaghegh, Kelly-Ann Blake, Kristen DonPaul, and Erin Pettibone for various kinds of help. I also want to thank the audience of the Workshop on Approaches to Coercion and Polysemy (CoPo 2017) at the University of Oslo for their feedback.

\section{REFERENCES}

de Almeida, Roberto G. 2004. The effect of context on the processing of typeshifting verbs. Brain and language 90(1-3). 249-261.

de Almeida, Roberto G. \& Veena D. Dwivedi. 2008. Coercion without lexical decomposition: Type-shifting effects revisited. Canadian Journal of Linguistics 53(2/3). 301-326.

Asher, Nicholas. 2011. Lexical Meaning in Context: A Web of Words. Cambridge University Press.

Balota, David A., Melvin J. Yap, Keith A. Hutchison, Michael J. Cortese, Brett Kessler, Bjorn Loftis, James H. Neely, Douglas L. Nelson, Greg B. Simpson \& Rebecca Treiman. 2007. The English lexicon project. Behavior Research Methods 39(3). 445-459.

Barr, Dale J., Roger Levy, Christoph Scheepers \& Harry J. Tily. 2013. Random effects structure for confirmatory hypothesis testing: Keep it maximal. Journal of memory and language 68(3). doi:10.1016/j.jml.2012.11.001. https ://www .ncbi. nlm.nih.gov/pmc/articles/PMC3881361/.

Briscoe, Ted, Anne Copestake \& Bran Boguraev. 1990. Enjoy the paper: lexical semantics via lexicology. In Proceedings of the 13th International Conference on Computational Linguistics, 42-47. Helsinki.

Egg, Markus. 2003. Beginning Novels and Finishing Hamburgers: Remarks on the Semantics of to begin. Journal of Semantics 20(2). 163-191. doi:10.1093/jos/20.2. 163. https://academic. oup.com/jos/article/20/2/163/1621112. 
Frazier, Lyn \& Steven Frisson. 2005. Carving up word meanings: Portioning and grinding. Journal of Memory and Language 53(2). 277-291.

Frisson, Steven \& Brian McElree. 2008. Complement coercion is not modulated by competition: Evidence from eye movements. Journal of Experimental Psychology: Learning, Memory, and Cognition 34(1). 1-11.

Fruehwald, Josef \& Neil Myler. 2015. I'm done my homework-Case assignment in a stative passive. Linguistic Variation 15(2). 141-168.

Honselaar, Wilhelmus J. J. 1980. Valenties en diathesen: een bijdrage tot russische valentie- en genustheorieën en een toepassing daarvan bij de semantisch-syntactische descriptie van enige verba, deictische woorden en preposities in het Nederlands. Universiteit van Amsterdam. Google-Books-ID: lbJyjgEACAAJ.

Jackendoff, Ray. 1997. The architecture of the language faculty. Cambridge, MA: MIT Press.

Katsika, Argyro, David Braze, Ashwini Deo \& Maria Mercedes Piñango. 2012. Complement coercion: Distinguishing between type-shifting and pragmatic inferencing. The Mental Lexicon 7(1).58-76.

Kuznetsova, Alexandra, Per Bruun Brockhoff \& Rune Haubo Bojesen Christensen. 2017. lmerTest: Tests in linear mixed effects models. https://CRAN. R-project. org $/$ package=lmerTest.

McElree, Brian, Matthew J. Traxler, Martin J. Pickering \& Rachel E. Seely. 2001. Reading time evidence for enriched composition. Cognition 78(1). B17-B25.

Moens, Marc \& Mark Steedman. 1988. Temporal ontology and temporal reference. Computational Linguistics 14(2). 15-28.

Piñango, Maria Mercedes \& Ashwini Deo. 2016. Reanalyzing the Complement Coercion Effect through a Generalized Lexical Semantics for Aspectual Verbs. Journal of Semantics 33(2). 359-408. doi:10.1093/jos/ffv003. https://academic. oup. $\mathrm{com} / \mathrm{jos} / \mathrm{article} / 33 / 2 / 359 / 2413887$.

Piñango, Maria Mercedes, Edgar Zurif \& Ray Jackendoff. 1999. Real-time processing implications of enriched composition at the syntax-semantics interface. Journal of Psycholinguistic Research 28(4). 395-414.

Pickering, Martin J., Brian McElree \& Matthew J. Traxler. 2005. The difficulty of coercion: A response to de Almeida. Brain and Language 93(1). 1-9.

Pustejovsky, James. 1991. The generative lexicon. Computational Linguistics 17(4). 409-441. 
Pustejovsky, James. 1995. The generative lexicon. Cambridge, MA: MIT Press.

Pylkkänen, Liina \& Brian McElree. 2006. The syntax-semantics interface: On-line composition of sentence meaning. In Matthew J. Traxler \& Morton A. Gernsbacher (eds.), Handbook of Psycholinguistics, vol. 2, 539-581.

R Core Team. 2017. R: A language and environment for statistical computing. R Foundation for Statistical Computing. https://www.R-project.org/.

Sweep, J. 2012. Metonymical object changes: a corpus-oriented study on Dutch and German. UtrechtLOT9789460930911. https://dare.uva.nl/search? identifier $=849907 \mathrm{fc}-\mathrm{d} 37 \mathrm{e}-4 \mathrm{e} 85-\mathrm{b} 567-\mathrm{b} 6 \mathrm{c} 74 \mathrm{c0627cc}$.

Traxler, Matthew J., Brian McElree \& Rihana S. Williams. 2005. Context effects in coercion: Evidence from eye-movements. Journal of Memory and Language 53(1). $1-25$.

Traxler, Matthew J., Martin J. Pickering \& Brian McElree. 2002. Coercion in sentence processing: evidence from eye-movements and self-paced reading. Journal of Memory and Language 47(4). 530-547.

Verspoor, Cornelia Maria. 1997. Contextually-Dependent Lexical Semantics, .

Yerastov, Yuri. 2008. I am done dinner: A case of lexicalization. In Proceedings of the 2008 annual conference of the Canadian Linguistic Association, Vancouver, BC.

Yerastov, Yuri. 2012. Transitive be perfect: An experimental study of Canadian English. Canadian Journal of Linguistics 57(3). 427-457.

AUTHOR CONTACT INFORMATION

Patrick Murphy

University of Toronto

p.murphy@mail.utoronto.ca 